\title{
هUCLM
}
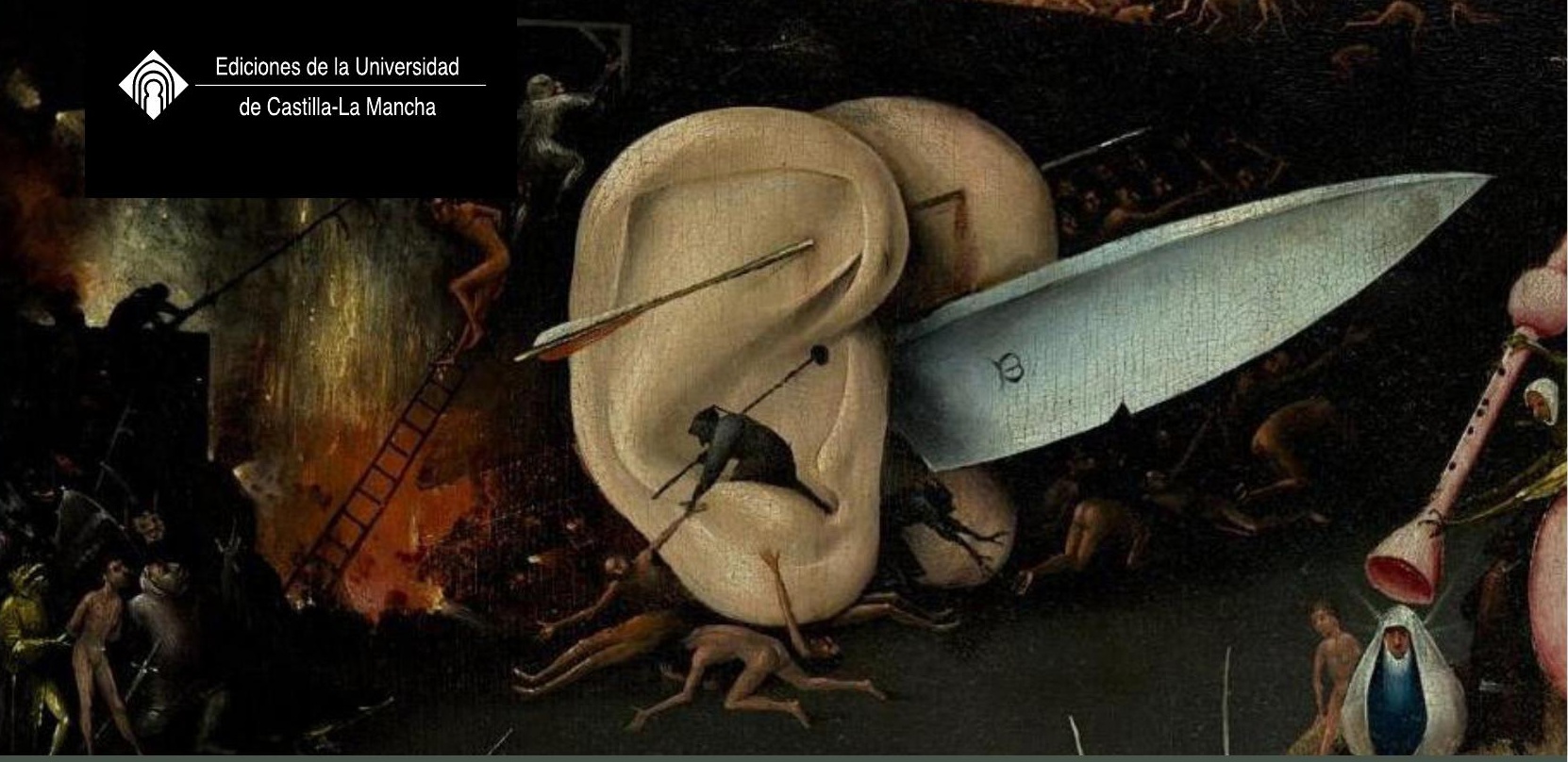

\section{La presencia del ausente}

\section{Dios en literatos contemporáneos}

Edición preparada por:

Juan Agustín Mancebo Roca Antonio Barnés

Alicia Nila Martínez Díaz

colección estudios 


\title{
LA PRESENCIA DEL AUSENTE
}

\section{Dios en literatos contemporáneos}

\author{
Albalá, Appleyard, Argullol, Bagli, Barnés, Batres, Blake, Bousoño, Buero, Cardenal, \\ Carrère, de las Casas, Cernuda, Champourcin, Contreras y López de Ayala, Cortázar, \\ Cotta, Cullen, Diego, Fernández, Fuertes, García Lorca, Gaos, Gomis, Guitton, \\ Houellebecq, Hughes, Jiménez, Lacaci, López Gorgé, López Anglada, Manrique de \\ Lara, Merino, Murciano, Nervo, Papini, Pascal, de la Rica, Swedenborg, Tolkien, \\ Vázquez, Villacañas, Waugh, Zardoya
}





\title{
LA PRESENCIA DEL AUSENTE Dios en literatos contemporáneos
}

Albalá, Appleyard, Argullol, Bagli, Barnés, Batres, Blake, Bousoño, Buero, Cardenal, Carrère, de las Casas, Cernuda, Champourcin, Contreras y López de Ayala, Cortázar, Cotta, Cullen, Diego, Fernández, Fuertes, García Lorca, Gaos, Gomis, Guitton, Houellebecq, Hughes, Jiménez, Lacaci, López Gorgé, López Anglada, Manrique de Lara, Merino, Murciano, Nervo, Papini, Pascal, de la Rica, Swedenborg, Tolkien, Vázquez, Villacañas, Waugh, Zardoya

\author{
Edición preparada por: \\ Juan Agustín Mancebo Roca \\ Antonio Barnés \\ Alicia Nila Martínez
}

Ediciones de la Universidad

Cuenca, 2021 
LA PRESENCIA del ausente : Dios en los literatos contemporáneos / Magdalena Aguinaga Alfonso... [et al. ] ; edición preparada por, Juan Agustín Mancebo Roca, Antonio Barnés, Alicia Nila Martínez Díaz.- Cuenca : Ediciones de la Universidad de Castilla-La Mancha, 2021

200 p. ; 24 cm.- (Estudios ; 173)

ISBN 978-84-9044-449-8 (edición electrónica)

1. Literatura - Historia y crítica I. Aguinaga Alfonso, Magdalena II. Mancebo Roca, Juan Agustín, ed. lit. III. Barnés, Antonio, ed. lit. IV. Martínez Díaz, Alicia Nila, ed. lit. V. Universidad de Castilla-La Mancha, ed. VI. Serie

82.09

DS

Cualquier forma de reproducción, distribución, comunicación pública o transformación solo puede ser realizada con la autorización de EDICIONES DE LA UNIVERSIDAD DE CASTILLA-LA MANCHA salvo excepción prevista por la ley.

Diríjase a CEDRO (Centro Español de Derechos Reprográficos - www.cedro.org), si necesita fotocopiar o escanear algún fragmento de esta obra.

(C) de los textos e imágenes: sus autores. 2021.

(C) de la edición: Universidad de Castilla-La Mancha. 2021.

Edita: Ediciones de la Universidad de Castilla-La Mancha

Colección ESTUDIOS n. ${ }^{\circ} 173$

Diseño de la colección y de la cubierta: C.I.D.I. (Universidad de Castilla-La Mancha)

Foto de cubierta: El jardín de las delicias (detalle). 1490-1500. Hieronymus Bosch, El Bosco. Museo del Prado.

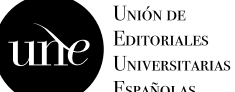

Esta editorial es miembro de la UNE, lo que garantiza la difusión y comercialización de sus publicaciones a nivel nacional e internacional.

ISSN-L: 2255-2618

I.S.B.N.: 978-84-9044-449-8 (Edición electrónica)

DOI: https://doi.org/10.18239/estudios_2021.173.00

Composición: Compobell

Hecho en España (U.E.) - Made in Spain (E.U.) 


\section{ÍNDICE}

Prefacio..................................... 9

Juan Agustín Mancebo Roca, Antonio Barnés y Alicia Nila Martínez.

Diálogo ficticio entre Jean Guitton y Blaise Pascal . . . . . . . . ...... 13 Magdalena Aguinaga Alfonso

¿Dónde está Dios? 30 poetas responden Antonio Barnés

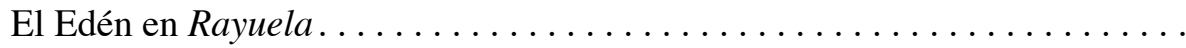
43 Izara Batres

Presencia y sentido de Dios en Irene o el tesoro (1954), de Antonio Buero Vallejo . . . . . . . . . . . . . . . . . . . . . . . . . . . . . . . . . . José Luis González Subías

Las memorias de Dios. Ateísmo, crisis y conversión de Giovanni Papini (1907-1921).

Juan Agustín Mancebo Roca

Más allá de las palabras: un estudio comparatista de la representación de la gracia, el pecado y la redención en la novela y la película Brideshead revisited......................................

Alicia Nila Martínez Díaz 
Tolkien: sobre la trascendencia desde el corazón artístico . . . . . . . . . 101 Jon Mentxakatorre Odriozola

«Un Cristo de color recrucificado»: Countee Cullen y el simbolismo religioso 117 Mario Millanes Vaquero

Fe cristiana y antropología teológica en la narrativa de José María Merino . . 133 José Ignacio Peláez Albendea

Metamorfosis de la religión y literatura postsecular. Aproximación sociológica y cultural a Rafael Argullol, Michel Houellebecq y Emmanuel Carrère ...... . Rafael Ruiz Andrés

La concepción de un Dios antropomorfo eterno y universal en Swedenborg y William Blake ... . . . . . . . . . . . . . . . . . . . . . . . . . . . . . . . . 169

Mónica Sánchez Tierraseca

Born from Pain and Fire: Mystical Symbolism and the Search for Cronopia in the poetry of Izara Batres Cuevas . . . . . . . . . . . . . . . . Robert Simon 


\section{PREFACIO}

El hombre contemporáneo bascula entre una razón mediática que lo imbuye de información fragmentaria, inmediata y reduccionista, y otra razón científica, que se debate de continuo sobre lo que puede o no afirmar. Emerge así la literatura como isla de libertad, no solo por la imaginación desatada en que se basa, sino porque permite bucear por los más recónditos espacios del alma humana sin gendarmes que detengan el paso, ni tiranías de lo inmediato.

Es lo que constata el "Proyecto Dios en la literatura contemporánea". Desde 2016, investigadores de Rusia, Bielorrusia, Alemania, Francia, Italia, España, Camerún, Estados Unidos, México y Venezuela trabajan para verificar si y cómo está presente Dios en la era del secularismo. En el libro que introducimos, gracias al mecenazgo de la Universidad de Castilla-La Mancha, doce investigadores abordan la escritura literaria de autores tan dispares como relevantes: Albalá, Appleyard, Argullol, Bagli, Barnés, Batres, Blake, Bousoño, Buero, Cardenal, Carrère, de las Casas, Cernuda, Champourcin, Contreras y López de Ayala, Cortázar, Cotta, Cullen, Diego, Fernández, Fuertes, García Lorca, Gaos, Gomis, Guitton, Houellebecq, Hughes, Jiménez, Lacaci, López Gorgé, López Anglada, Manrique de Lara, Merino, Murciano, Nervo, Papini, Pascal, de la Rica, Swedenborg, Tolkien, Vázquez, Villacañas, Waugh, Zardoya y un nutrido grupo de poetas hispánicos. Son escritores de diferentes lenguas (cinco) y literaturas a un lado y otro del Atlántico. Representan todos los géneros: lírica, teatro, narrativa y ensayo, y pertenecen a los tres últimos siglos.

La literatura no sabe de religiones encerradas en el ámbito privado. El anticlericalismo y nihilismo de Papini y su ulterior conversión se escenifican y clarifican en sus obras literarias, como expone el profesor Juan Agustín Mancebo en su capítulo "Las 
Memorias de Dios. Crisis y conversión en Giovanni Papini”. Otros autores, como William Blake han escrito toda su obra desde un estado de profetismo religioso. Lo estudia Mónica Sánchez Tierraseca en "Representación del swedenborgianismo en William Blake". Lo religioso sirve de referente para cuestiones de gran calado antropológico y social, como el racismo. Lo vemos en el capítulo que desarrolla Mario Millanes en "Un Cristo de color recrucificado": Countee Cullen y el simbolismo religioso". El misticismo o la expresión de lo inefable no es una veta del pasado. El investigador norteamericano Robert Simon, de la Kennesaw State University, quedó fascinado por el estro poético de la poeta española Izara Batres, sobre la que escribe y publica en este libro: "Born from Pain and Fire: Mystical Symbolism and the Search for Cronopia in the poetry of Izara Batres Cuevas". El ensayo, género híbrido de filosofía y literatura, permite viajes que la filosofía académica no vería con buenos ojos. Es lo que encontramos en el capítulo de Magdalena Aguinaga: "Mi testamento filosófico: diálogo ficticio entre Jean Guitton y Blaise Pascal”.

Y como la riqueza y profundidad del fenómeno religioso y sus interpretaciones no se agota en lo inmanente, sino que desborda siempre los límites pautados, en el presente volumen se encuentran también otros trabajos que abordan la cuestión de la presencia o ausencia de Dios desde la perspectiva de la lejanía, del ateísmo o el agnosticismo. Autores aparentemente distanciados de Él, pero igualmente interrogados. Es el caso de "Presencia y sentido de Dios en Irene o el tesoro (1954), de Antonio Buero Vallejo", donde José Luis González Subías nos descubre cómo la postura agnóstica del autor no es óbice para preguntarse acerca del sentido del Misterio en la vida de los hombres. Por su parte, Jon Mentxakatorre profundiza en la dimensión teológica en la obra de J.R.R. Tolkien. Tomando como punto de partida textos de El Silmarillion, Mentxakatorre muestra la estrecha relación existente entre el corazón humano, siempre proclive a la búsqueda de la belleza, y la dimensión divina, en el artículo "Tolkien: sobre la trascendencia desde el corazón artístico".

La mirada sagaz de los autores firmantes del volumen nos invita a explorar las intrincadas relaciones sostenidas entre el actual fenómeno de secularización que vivimos y la presencia del elemento religioso en distintos escritores contemporáneos. Para ello, Rafael Ruíz presenta un completo estudio sobre las obras de Rafael Argullol, Michel Houellebecq y Emmanuel Carrère. Tres novelistas en cuyas páginas se rastrea la presencia del Autor. Quien también se plantea la búsqueda y el encuentro con Dios es Antonio Barnés. En una completa nómina de poetas contemporáneos, nos muestra que hallamos a Dios en los lugares más insospechados. Decía Santa Teresa que estaba entre los pucheros, pero para los vates citados se encuentra también en la naturaleza, entre la niebla, en el tranvía y en el pan blanco de cada día. En suma, en la cotidianeidad del ser humano. José María Merino es otro de los literatos aquí estudiados. José Ignacio Peláez pone 
de manifiesto la antropología cristiana subyacente en la poética de este escritor gallego, así como igualmente se ocupa de señalar cómo algunos de los principales males de los que adolece el ser humano aparecen magníficamente representados en los personajes de las novelas de Merino.

Tienes entre tus manos lector, una panoplia de aproximaciones al Autor de autores rica y muy original; pródiga en lo que a géneros, creadores y obras literarias se refiere; tan bizarra en sus reflexiones hermenéuticas, como sagaz en sus interrogaciones e interpretaciones acerca del dónde, el cómo o el cuándo se produce el encuentro del hombre con su Autor. Pero, ante todo, prudente y discreta en sus ponderaciones.

Un libro inusual, en suma, que invita a la lectura atenta y a la reflexión pausada. Actividades casi ya impropias del mundo que habitamos, pero quizá, por ello, más esenciales que nunca. Y con este ánimo lo presentamos. Con el deseo de su encuentro con todos aquellos lectores inquietos, buscadores impenitentes del Autor.

Juan Agustín Mancebo Roca Antonio BARNÉS Alicia Nila MARTínEZ Madrid-Albacete, febrero de 2021. 



\title{
PRESENCIA Y SENTIDO DE DIOS EN IRENE O EL TESORO (1954), DE ANTONIO BUERO VALLEJO
}

\author{
JOSÉ LUIS GONZÁLEZ SUBÍAS \\ Academia de las Artes Escénicas de España \\ https://orcid.org/0000-0002-4055-9293 \\ https://doi.org/10.18239/estudios_2021.173.04
}

Resulta sorprendente, y no parece casual, que un número significativo de obras del teatro español que abordaron, en el siglo Xx, el tema de la fe y la presencia de Dios en nuestras vidas fueron escritas y representadas en la década de los cincuenta: La ciudad sin Dios, de Joaquín Calvo Sotelo, en 1957; La sangre de Dios, de Alfonso Sastre, llevada a escena en 1955; o la que traemos como objeto de estudio y reflexión a estas páginas: Irene o el tesoro, de Antonio Buero Vallejo, estrenada en el Teatro María Guerrero, el 14 de diciembre de 1954.

Las inquietudes existenciales extendidas por toda Europa tras la Segunda Guerra Mundial, que tuvieron su reflejo en el teatro del absurdo, se plasmaron también en una escena española aparentemente acomodada en una evasiva y convencional dramaturgia calificada, con un sentido peyorativo, como burguesa, que se hizo eco asimismo, en algunos momentos, de un intenso y crucial debate sostenido ya desde el siglo anterior en torno a la presencia, o la carencia, de Dios en el mundo contemporáneo. Este conflicto, que en ocasiones, como en la obra de Calvo Sotelo mencionada, se plantea desde posicionamientos políticos muy evidentes, adquiere en otros casos matices netamente existencialistas, de raigambre unamuniana, relacionados con la duda racional en torno a la existencia de Dios y la necesidad emocional $-\mathrm{y}$ vital - de creer en esta. Un debate, en definitiva, en torno a la fe. Irene o el tesoro 
participa plenamente de esta disyuntiva, desde un posicionamiento por parte de su autor que nos invita a entender el texto en clave teológica y otorgar a su mensaje un sentido trascendente de raigambre cristiana.

Si bien existe un amplio consenso entre los muchos estudiosos del teatro de Antonio Buero Vallejo respecto al mensaje generalmente esperanzador de su obra, sin perder por ello su esencialidad trágica, son muy pocos los que han prestado atención a la presencia del elemento religioso o divino en algunos de sus textos. Es preciso remontarse a los años mismos en que se escribieron sus primeras obras, $y$ en concreto la que nos ocupa, para encontrar entre los críticos que las valoraron una interpretación en este sentido. Así lo hicieron Rosendo Roig o José María García Escudero, desde revistas como Razón y Fe o Punta Europa, afines al ideario del régimen nacional-católico de su tiempo, quienes consideran que «el punto de vista ético de Buero Vallejo es cristiano» (Michael Atlee, 1972: 54); o Nicolás González Ruiz desde las páginas del Ya (15-XII-1954), al día siguiente del estreno de la obra, en la que ve «una demostración de los dones que nos hace la misericordia de Dios». Sin embargo, resulta difícil encontrar con posterioridad opiniones semejantes.

Quizá el autor más cercano a estas tesis, todavía próximo en el tiempo a aquellos, sea el profesor estadounidense A. F. Michael Atlee, quien en 1972 publicó, en la revista Hispanófila, el único artículo académico expresamente dedicado a este tema hasta hoy. En su escrito, que lleva por título «Antonio Buero Vallejo y Dios», Atlee afirma que «el punto ético de Buero Vallejo no está basado en la fe católica, y sin embargo, no puede decirse que no lo sea» (1972: 53). Si bien la solución que el dramaturgo ofrece en sus textos a los conflictos humanos se encuentra en el amor y el perdón, al igual que en el cristianismo - bien es cierto que también en otras religiones-, el suyo no podrá ser nunca un punto de vista cristiano, afirmaba el estudioso norteamericano, «por la sencilla razón de que es agnóstico» (Michael Atlee, 1972: 54).

Aceptamos el componente esencialmente agnóstico de Buero Vallejo respecto a un tema, el de la trascendencia y el misterio que rodea al hombre, que tanto le interesa; pero consideramos el suyo un agnosticismo esperanzado. Es verdad también que, en sus obras, el autor pretende ofrecer una imagen de aparente imparcialidad respecto a las decisiones que deben tomar sus personajes, dejando que sean estos quienes elijan su camino y haciendo recaer sobre ellos la responsabilidad de sus actos; pero esto, sin dejar de ser un rasgo «humanista» (Michael Atlee, 1972: 54), responde a un libre albedrío que forma parte consustancial de la salvación y el pecado en la tradición cristiana. El mismo Atlee, desde su negación de que el concepto de Dios en Buero Vallejo sea cristiano, no deja de defender la presencia de la religiosidad en su obra: «El hecho de que Buero Vallejo crea que todo en la existencia social del hombre sea de naturaleza humana no significa que 
él no permita a sus personajes un sentimiento religioso y que no trate de dar una definición de Dios» (Michael Atlee, 1972: 55).

Afirma el hispanista norteamericano que, con excepción de Palabras en la arena - excepción que justifica viendo este texto como una «referencia de naturaleza histórica»-, nunca se habla de Cristo o de Dios en las obras de Buero Vallejo (Michael Atlee, 1972: 54, 56). Sin embargo, no solo en esta temprana pieza del dramaturgo basada en el conocido pasaje bíblico en que Jesús - siempre presente, aunque nunca físicamente, en escena- salva a una mujer adúltera de morir lapidada, la presencia del Dios cristiano se hace palpable; también en un texto tan diferente a este, como es la fábula en tres actos titulada Irene o el tesoro, una entidad misteriosa, de cuya realidad el autor nos hace dudar, solo perceptible a través de su Voz — «Una voz que no se sabe de dónde viene [...] una voz grave, serena y bondadosa: una voz absolutamente excepcional», según la describe el dramaturgo en su primera aparición (I, 32) - , remite en todo momento a una esencia divina que no resulta difícil identificar con el concepto mismo de un Dios que, en el principio, se manifestó también a través de la palabra: «en el principio era el Verbo [...], y el Verbo era Dios» (Juan 1:1).

En una premeditada ambigüedad del autor, que juega permanentemente con el equívoco en el texto (Buero Vallejo, 1955: 118), este deja en el misterio la identidad de un ser indefinido que solo se manifiesta con la palabra y rechaza con rotundidad la mera insinuación de ser identificado con Dios:

LA VOZ: ¿Por qué de rodillas?

JUANITO: Yo creo que tú eres Dios.

LA VOZ: Levántate y no pronuncies esa palabra. Es demasiado elevada para todos nosotros.

JUANITO: (Se levanta.) ¿Quién eres tú? (Silencio.) ¿Eres un ángel? (Silencio.) (III, 110)

Una respuesta que para el crítico estadounidense mencionado es suficiente prueba de que la Voz «no es Dios» (Michael Atlee, 1972: 56); pero que, en nuestra opinión, sigue jugando con esa ambigüedad pretendida por Buero en su texto. La misteriosa Voz no desea, no necesita, explicar quién es; y, sin embargo, su respuesta cercana, humilde, piadosa, está impregnada de divinidad.

Lo cierto es que, en los últimos cincuenta años, resulta muy difícil encontrar no solo algún interés por esta sugerente pieza - a nuestros ojos, llena de valores dramáticos, y humanos - , sino cualquier asomo de interpretación teológica en quienes se han acercado alguna vez a ella. A lo sumo, ha sido vista como un ejemplo más del mensaje de fe y esperanza que han reconocido algunos estudiosos en la obra de Buero Vallejo (Doménech, 1973; Ruiz Ramón, 1981; González Subías, 2020), 
en la línea de otros autores de su tiempo, como Alejandro Casona o Joaquín Calvo Sotelo, por poner algún ejemplo. Ruiz Ramón, sin llegar a interpretar la obra en un sentido religioso, encuentra en esa Voz, en cuya esencia reside la clave interpretativa del texto, el «signo de una invisible presencia» (1981: 352), sin ahondar más en esta, limitándose a considerarla una manifestación del misterio que envuelve y rodea al ser humano (1981: 353). César Oliva, en una interpretación totalmente alejada de lo divino, la consideró una «presencia del demiurgo creador», lo que convierte al autor en «un dios doméstico» (1989: 242). E Iniesta Galvaño se muestra absolutamente escéptico con la existencia misma de una voz que solo oyen «los locos, como Irene. Y los duendes» (2002: 218).

Sin embargo, a pesar de haber confesado su falta de fe tras abandonar la «honda fe acrítica» de su infancia, en una entrevista concedida al profesor Mariano de Paco el propio Buero Vallejo confirma su interés por lo divino, «sencillamente porque me interesa el enigma del mundo y ese enigma no está resuelto. Y acaso porque, como alguna vez he dicho, la estructura de mi pensamiento es religiosa aunque yo no crea» (De Paco, 1994: 14). Y ese «punto de vista de Dios», mencionado por Vicente en El tragaluz, «que nunca tendremos, pero que anhelamos», como le contesta Mario, es una muestra no solo del agnosticismo esperanzado del autor, al que aludíamos antes, sino también del «notable peso específico» que la cuestión de Dios tiene «en su dramaturgia y en su vida personal» (Rodríguez, 2016: s. pág.).

No nos atrevemos a cuantificar el peso de este interés, pero sí afirmamos que dicho interés existe, y se manifiesta con claridad en Irene o el tesoro. Son muchas las pistas que creemos encontrar en un texto en el que su autor, como él mismo confiesa, jugó premeditadamente con la ambigüedad y el equívoco (Buero Vallejo, 1955: 122). Todo son sugerencias en esta historia en que los planos de la realidad y lo irreal se superponen, sin posibilidad de distinguir dónde se halla la verdad y dónde la imaginación o el delirio. Desde la perspectiva de los personajes que rodean a Irene, una joven huérfana y viuda que vive sojuzgada y humillada en el hogar de los padres de quien fue su marido durante solo un mes, al fallecer este, y perdió también a su hijo, que nació muerto, el extraño comportamiento de la joven es fruto de su enajenación mental. Pero la realidad de Irene es otra. Tratada como una sufridora Cenicienta - en su presentación en escena, aparece «fregando el suelo de rodillas y con el cubo al lado» (I, 10) - por sus seres más cercanos, con los que convive, sobrevive refugiada en un mundo de ensoñación infantil ligado a los cuentos de «hadas y ogros, y asnos encantados» que leyó de niña; un mundo de fantasía donde «las montañas estaban llenas de diamantes y en la casas viejas había siempre tesoros escondidos»; y «por los túneles de las montañas, y en las casas, corrían los duendes», que «siempre eran amigos de una linda princesa» (I, 14-15). Por supuesto, la princesa que espera ser salvada de la angustia en que vive es ella. 
Vemos, por tanto, que el personaje central de esta fábula en tres actos es el punto de conexión entre los dos planos mencionados, el de lo real y lo maravilloso. Este último, representado por un duende que se le aparece en mitad de una de sus crisis — «un gentil duendecito de pecosos mofletes y ágiles piernecillas, enfundado en su medieval atuendo verde»- y por esa Voz «que no se sabe de dónde viene» y reclama a su enviado que busque el tesoro escondido en la casa (I, 31-32). Si el duendecillo - de nombre Juanito, con lo que se desvanece cualquier posibilidad de ofrecer una dimensión sagrada del personaje $-{ }^{1}$ se encuentra muy alejado del mundo de la divinidad, sobre todo cristiana, siendo representativo, más bien, del imaginario de la fantasía, no ocurre así con la Voz, que investida de un poder sobrehumano, parece mover los hilos de una trama en la que su voluntad decide el destino que corresponde a cada uno de los personajes que la conforman, en virtud de su actos y de la nobleza de su corazón, impartiendo una justicia que no dudamos en calificar de divina. Justicia acorde con el fin moral que el dramaturgo pretende dar asimismo a su pieza al denominarla «fábula», término que, como aclara en el comentario que añadió a la edición de su texto, en 1955, no solo alude a una «narración o suceso ficticio en que intervienen seres maravillosos», sino también a «aquella otra en la que por medios simbólicos o alegóricos se expresa una enseñanza moral». Y esta obra, concluye, «es una fábula por su duendecito, mas también lo es por sus contenidos éticos» (Buero Vallejo, 1955: 118-119).

Son muchas las insinuaciones que Buero Vallejo va vertiendo a lo largo de la pieza, ofreciéndonos pistas que arroja al arbitrio de nuestra interpretación, como deja libertad para que el espectador - o lector, en su caso - otorgue a su texto el sentido que considere oportuno. Ahora bien, no todas las interpretaciones tienen la misma validez para él:

Entre la perspectiva, por ejemplo, de Irene sola y deshecha sobre las piedras de la calle que ven los personajes al final de la obra, y la de Irene acompañada de su niño alejándose por un camino de luz que ve el público, es más bella y piadosa esta última; y solo por eso quedamos ya autorizados para suponer que, de algún modo, también es más cierta (Buero Vallejo, 1955: 123).

El sentido e intención básicos del texto se anuncia desde el título mismo con que este se presenta, Irene o el tesoro, con el empleo de una conjunción que no es disyuntiva, sino explicativa, como el mismo autor aclara: Irene es el tesoro que el duende debe buscar (Buero Vallejo, 1955: 118), sin que este lo sepa durante la mayor parte de la obra; a lo largo de la cual, quienes contemplamos cuanto suce-

1 Si bien es cierto que no deja de ser el diminutivo - afectivo, cercano - de Juan, uno de los apóstoles más queridos por Jesús y cuyo nombre, en hebreo, representa la fidelidad a Dios. 
de en la representación hemos tenido tiempo más que suficiente para percibir la presencia de Dios en escena. Desde los primeros momentos las alusiones a este son recurrentes. Ya lo hace Sofía - junto a Irene, el personaje mejor retratado en el texto-, la anciana y bondadosa hermana de Justina, al pretender descargar de responsabilidad a esta y a su hija Aurelia - suegra y cuñada, respectivamente, de Irene - arguyendo que «Él las ha hecho así»; o en la misma conversación, poco más tarde, al afirmar: «Dios nos juzgará a todos»; y, finalmente, «Cose, hija, cose. Dios te ayudará: tú lo verás» (I, 28-30).

El sentido exacto de la obra se insinúa ya, con claridad, en estas palabras: Dios juzgará el comportamiento de los individuos que habitan en esa casa y ayudará a Irene a librarse del sufrimiento en que vive. Un sufrimiento ligado escenográficamente a la «Habitación destartalada en un caserón del barrio viejo de la ciudad», donde se desarrolla la acción (I, 10), y manifestado en la permanente oscuridad que Irene percibe a su alrededor y no deja de recordar en sus intervenciones. El contraste entre la luz y la oscuridad es reiterado en la dramaturgia de Buero Vallejo ya desde la primera de sus obras, En la ardiente oscuridad, identificándose aquella, en alguna ocasión, incluso con Dios mismo: «He llegado a sospechar que la forma misma de Dios, si alguna tiene, sería la luz...», manifiesta el personaje de Velázquez en Las Meninas, en una cita repetidas veces utilizada (De Paco, 1998: 191; Callejas Berdonés, 2008: 182). Como afirmó en su momento Ignacio Elizalde: «En Buero, la verdad es luz» (1972: 436). ¿Y acaso no dijo Jesús: «Yo soy la luz del mundo; el que me sigue no andará en tinieblas» (Juan 8:12)?

También en Irene o el tesoro el contraste entre la luz y las sombras, y los prodigios que se producen en escena en torno a aquella, la convierten en un mecanismo simbólico de extraordinario valor, asociado a lo maravilloso y, en última instancia, a lo divino. Cuando, por indicación de la Voz - una voz que solo puede escuchar el duende-, se abre el balcón por donde finalmente abandonará Irene este mundo, se observa una premonitoria escena, llena de significado: «Tras la barandilla muéstrase ahora un milagro de viva luz blanca. Parece como un corredor que, en rampa suave, llega hasta el balcón en extrañas e irregulares paredes de diamantina claridad» (II, 62).

La simbología de esta obra es lo bastante evidente y precisa como para, a pesar de su pretendida ambigüedad, permitirle al autor expresar su mensaje claramente. «Dios mío: si es verdad que tú puedes dar el consuelo que cada uno necesita, alíviame esta horrible oscuridad y dame el mío... pronto» (I, 42), reclama suplicante Irene, a la que el duende mira con ternura, sin poder aún ser visto por esta. A la pregunta de si está loca, la Voz responde a su enviado: «Por lo menos, es muy desgraciada» (I, 42).

La visión de este mundo como un lugar de sufrimiento y tristeza, como un valle de lágrimas donde el amor al prójimo es apenas perceptible, está muy presente en 
la obra. Así describe la Voz, a Juanito, el lugar donde ha sido enviado: «Has venido a una casa bien triste, hijo mío. Y hay muchas así. En todas ellas viven, como aquí, pobres seres que solo alientan para sus mezquindades, sin sospechar siquiera que el misterio los envuelve» (II, 46). Este ser, que se dirige al duende llamándolo «hijo mío», y al que este corresponde del mismo modo cuando le ruega por Irene de rodillas — «Padre mío: yo te pido que la salves» (II, 46) - , atribuyéndole asimismo, junto al de la omnipotencia, el don de la omnisciencia — «tú lo sabrás», «lo que tú no sepas...» (II, 46) - , alude con frecuencia al misterio de la vida y de cuanto nos rodea, de cuya sustancia todo está hecho, incluso el propio duende: «También tú estás hecho de la sustancia del misterio», le dice (II, 46). Misterio del que también es consciente Daniel, el licenciado en Filosofía enamorado de Irene, que se hospeda en la casa y malvive dando clases particulares:

Ya sabes que no soy más que un pobre soñador... Y todos los soñadores sabemos que el mundo no es solo esta sucia realidad que nos rodea: que en él también hay, aunque no lo parezca, una permanente y misteriosa maravilla que nos envuelve. [... ] Y esa maravilla nos mira, nos vigila y nos penetra... Y, algún día, puede que logremos verla cara a cara (III, 86).

Esa capacidad, reservada para los soñadores y los locos, fue la que tuvieron asimismo místicos como Santa Teresa y San Juan de la Cruz, a quienes cita Daniel - nombre de profeta - relacionándolos de algún modo con Irene: «También ellos vivían en un mundo donde les pasaban cosas maravillosas... Locos les decían. Y es que eran santos. [...] Yo te comprendo ya, mi santita» (III, 86).

«Los locos son ellos», confirma la Voz en otro momento (III, 97), instando al duende a cumplir con su obligación de buscar el tesoro, y advirtiéndole de que, si no lo encuentra, no puede culpar a otra cosa más que a su falta de fe (III, 93). Una fe imperturbable en Irene, pero que llega a quebrarse incluso en Juanito, como les ocurriera a los propios discípulos de Jesús en algún momento: «Dime si todo esto es verdad. Dime si yo soy verdad y si lo eres tú, pues solo así creeré que ella no está loca» (III, 110).

Cuando por fin encuentran un tesoro en forma de monedas de oro, que solo pueden ver Irene y Juanito, estas tienen grabada una palabra: Bondad. «Son pocos los que pueden ver el tesoro de la bondad, hijo mío», le explica al duende la Voz (III, 102); para confirmar definitivamente: «El tesoro es ella» (III, 110).

La marcha final de Irene, guiada por el duende, a quien coge en sus brazos como si fuera su hijo, siguiendo ese «maravilloso camino de luz» que días antes se había ofrecido a sus ojos en el lugar donde se encuentra el balcón, y tras perdonar a todos los habitantes de la casa que abandona -inevitable pensar de nuevo en 
aquel «Padre, perdónalos, porque no saben lo que hacen» (Lucas 23:24) —, ofrece, a nuestros ojos, un mensaje de inequívoca esperanza y belleza poética. La pasión y muerte de Irene la convierte en una víctima de los hombres, redimida para el cielo por atesorar el mayor de los bienes humanos: la bondad.

El agnóstico esperanzado que fue Buero Vallejo vertió en esta obra sus sueños más elevados - entre los que se encuentra la existencia de un Dios de bondad que imparte justicia-, permitiéndose creer en ellos, aunque fuera bajo el marco poderoso de la ficción poética; pues, como afirma la cita de Unamuno con que encabeza la primera edición de su texto, es este «el secreto del alma redimida: / vivir los sueños al soñar la vida».

\section{REFERENCIAS BIBLIOGRÁFICAS}

Buero Vallejo, A. (1955): Irene o el tesoro. Madrid: Alfil.

Callejas Berdonés, J. M. (2008): Aproximación al teatro filosófico de Antonio Buero Vallejo. Madrid: Universidad Complutense.

De PACO, M. (1994): De re bueriana: (sobre el autor y las obras). Murcia: Universidad de Murcia.

De Paco, M. (1998): «Planos de significación en el teatro de Antonio Buero Vallejo». En A. M. Leyra (ed.). Antonio Buero Vallejo. Literatura y filosofía (pp. 185-194). Madrid: Editorial Complutense.

DomÉNeCH, R. (1973): El teatro de Buero Vallejo. Una meditación española. Madrid: Gredos.

ElizALDE, I. (1972): «Buero Vallejo». Cuadernos Hispanoamericanos, 261, pp. 432-449.

GonZÁlez Ruiz, N. (1954): «Irene o el tesoro en el María Guerrero». YA (15 de diciembre).

GonZÁlez Subías, J. (2020): José Luis. La dramaturgia española durante el franquismo. Madrid: Punto de Vista Editores.

InIESTA GalvaÑ, A. (2002): Esperar sin esperanza. El teatro de Antonio Buero Vallejo. Murcia: Universidad de Murcia.

Michael Atlee, A. F. (1972): «Antonio Buero Vallejo y Dios». Hispanófila, 44, pp. 53-57.

Oliva, C. (1989): El teatro desde 1936. Madrid: Alhambra.

RodríGuez, J. C. (2016): «Buero Vallejo y el punto de vista de Dios». Vida Nueva, 3004. [16, febrero, 2021] <https://www.vidanuevadigital.com/2016/09/23/buerovallejo-y-el-punto-de-vista-de-dios-centenario-nacimiento/>

Ruiz Ramón, F. (1981): Historia del teatro español. Siglo XX. Madrid: Cátedra (5a ed.). 